\title{
The Emerging Issue of Solid Waste Disposal Sites Emissions in Developing Countries: The Case of Brazil
}

\author{
André Luiz Bufoni1, Marcia da Silva Carvalho², Luciano Basto Oliveira3, \\ Luiz Pinguelli Rosa ${ }^{1}$ \\ ${ }^{1}$ Energy Planning Program, Federal University of Rio de Janeiro, Rio de Janeiro, Brazil \\ ${ }^{2}$ Accounting Department, Federal University of Rio de Janeiro, Rio de Janeiro, Brazil \\ ${ }^{3}$ IVIG_International Virtual Institute of Global Changes, Federal University of Rio de Janeiro, Rio de Janeiro, Brazil \\ Email: bufoni@facc.ufri.br
}

Received 19 May 2014; revised 15 June 2014; accepted 12 July 2014

Copyright (C) 2014 by authors and Scientific Research Publishing Inc. This work is licensed under the Creative Commons Attribution International License (CC BY). http://creativecommons.org/licenses/by/4.0/

(c) $\underset{\mathrm{EY}}{\mathrm{i}}$ Open Access

\section{Abstract}

While the main concerns with municipal solid waste in developed countries like the European Union and the United States are to reduce and recycle the energy recover in order to drastically reduce the residues disposal to landfill, for developing countries the targets on waste management are much more basic. This seems to be the case in Brazil that with a new regulation, it still attempts to eradicate the inadequate waste disposal for open dumps. Thus, the aim of this paper is to depict the context, the criteria and discuss the strategies used for: the municipalities achieve the goals and adhere the plan; choice and configuration of disposal sites; and economic instruments adopted and bringing the whole scenario to discussion, including methane emissions inventory thru the case study of the Rio de Janeiro State. The Rio de Janeiro State municipal solid waste management scenario has drastically changed in last five years from $9 \%$ of residues sent to adequate destinations, to the perspective of eradication of open dumps before the end of 2014. The results indicate that only adequate disposal of waste is mandatory with the prevalence of the sanitation approach. The evidences also indicate that planning goals to reduce waste are modest and the landfill gas recover is generally accepted as the optimal solution. This paper concludes that, unless the stakeholders add to the plan a more aggressive policy to increment, the competitiveness of other waste technologies that favor the landfilling reduction and energy recover, Rio de Janeiro State will face the increase of landfill numbers and sizes, management cost, environmental and leachate impact, post-closure care expenses, contaminating life-span, and methane emissions.

\section{Keywords}

Landfill Gas, Strategy, Greenhouse Gas, Waste Management 


\section{Introduction}

While the United States reuses, recycles and recovers 54\% of their municipal solid waste (MSW) [1], in some countries of West Europe the destination to landfills is almost over (Figure 1), the attention in developing countries is far basic and directly related to public health maintenance [2], as the reduction and the adequate destination of MSW. This is the case of Brazil that until 2008 it still sent almost 50\% (183 thousand tonnes per day) (1 tonne $=1000 \mathrm{~kg}$ ) to inadequate destinations (open dumps) [3].

However, Brazil recently launched the National Policy of Solid Residues (NPSR) that not only forbids the inadequate waste disposal, but also incorporates modern concepts of waste management as (MMA, 2012): 1) sectorial agreements; 2) life cycle and 3) joint responsibility; 4) reverse logistics; 5) compulsory waste selective collection; 6) final destination minimization (reuse, recycle, recover); and 7) waste-to-energy solution stimuli.

In this context, Rio de Janeiro State is responsible for 7\% or 16,163 tonnes/day from 92 municipalities of 15 million habitants. From the total, in 2007 only 4 cities sent $9 \%$ of the residues to adequate landfills; 12 cities sent $36 \%$ to controlled or remediated open dumps [5]. The rest of the 72 municipalities, or $41 \%$, disposed their waste at open dumps indiscriminately, including the capital. These rates are below all other states of southeast region which sent only $18.7 \%$ to open dumps.

Despite of the negative picture, since then, many facts emerged and converged to support a radical change in attention, and in how the municipal waste is managed. The Figure 2 depicts the MSWM evolution. Rio de Janeiro State expects to eradicate open dumps in 5 years, by 2014.

The aim of this paper is to depict the context, the criteria and discuss the strategies used for: the municipalities achieve the goals and adhere the plan; choice and configuration of disposal sites; and economic instruments adopted and bringing the whole scenario to discussion. This work also estimates the changes in carbon that will be stored and emitted at SWDS using the First Order Decay (FOD) described in Chapter 3 of 2006 IPCC Guidelines for National Greenhouse Gas Inventories.

\section{Case Study of Rio de Janeiro Waste Management}

\subsection{Regulatory Environment and Government Programs}

The crucial factor that sustained not only the Rio de Janeiro but the national waste management change was the

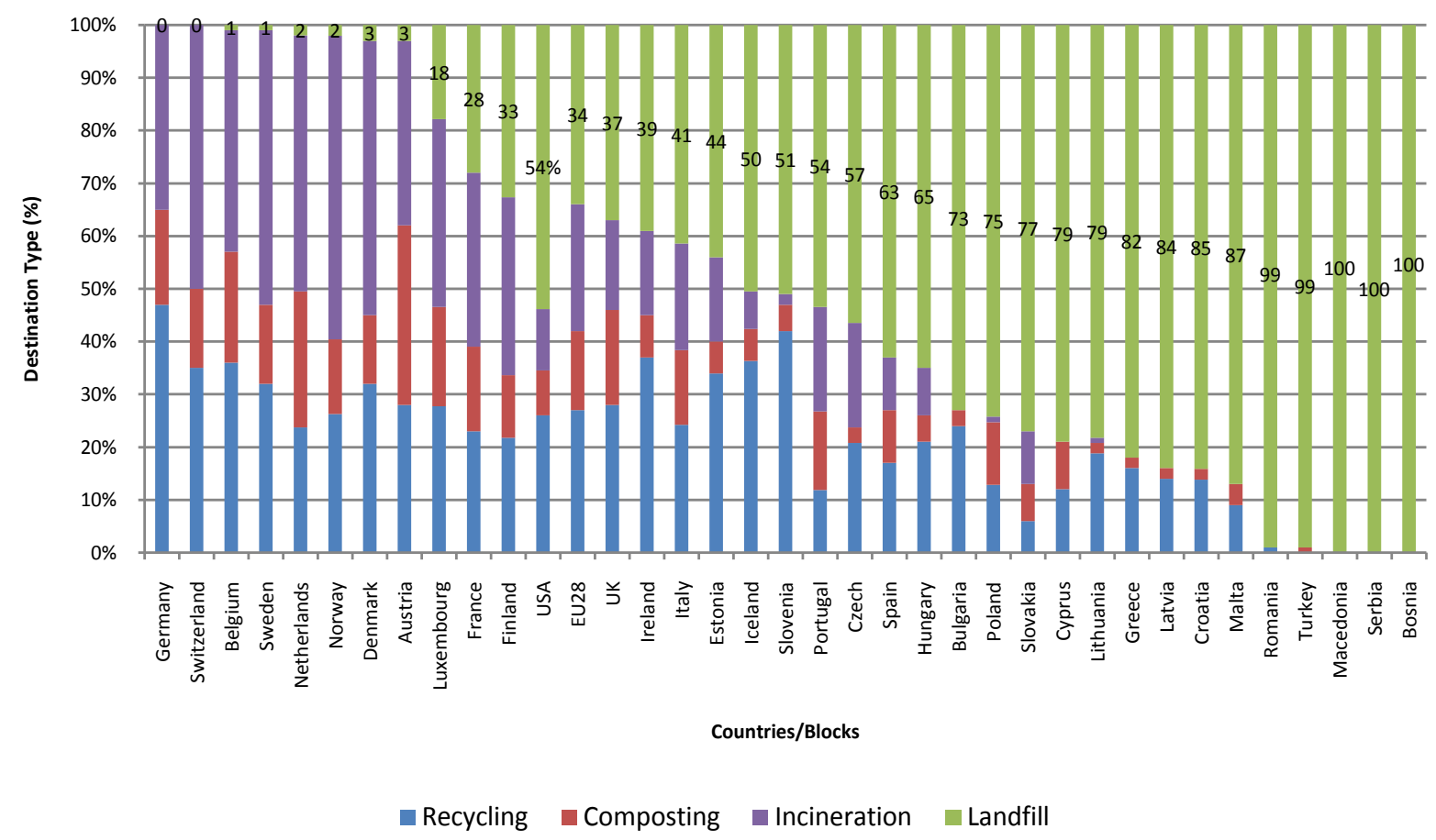

Figure 1. Waste destination USA and EU (2012). Source: adapted from EUROSTAT [4]. 


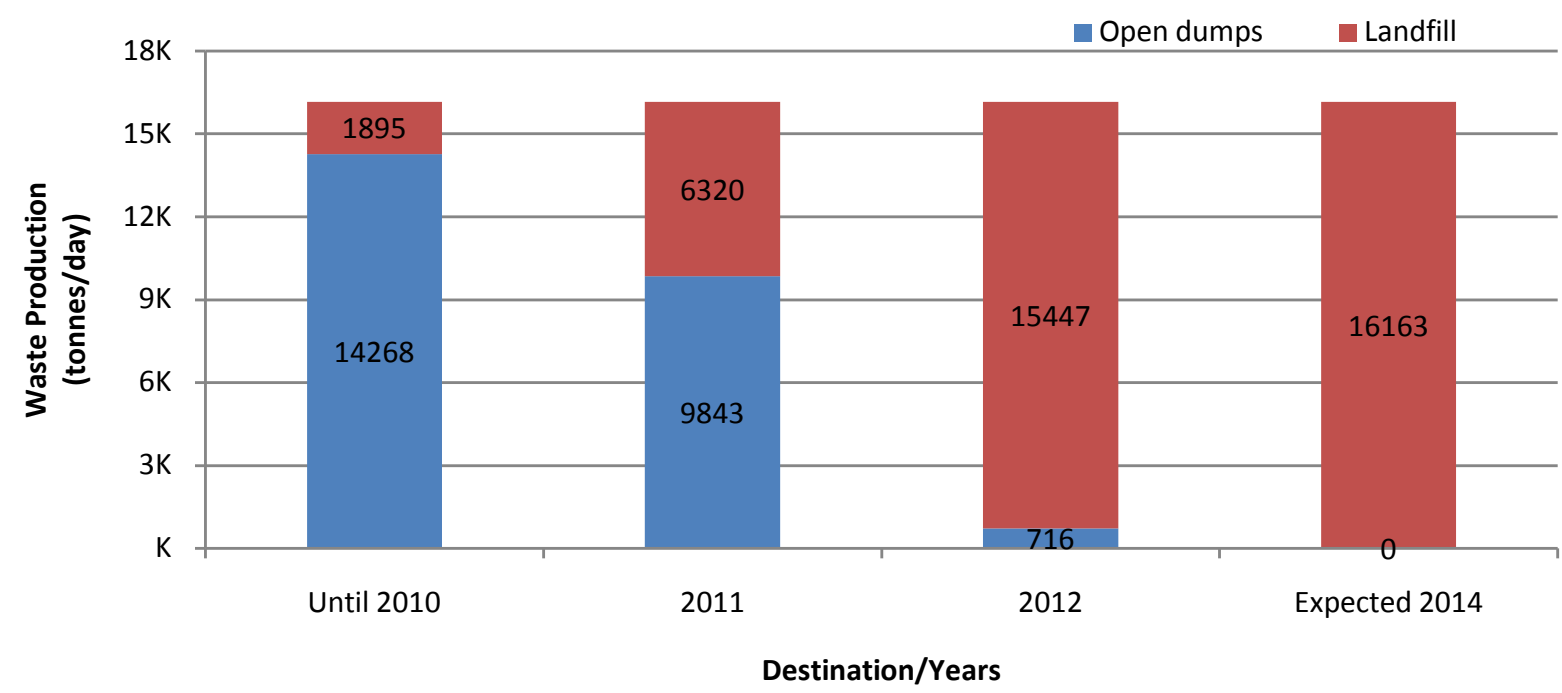

Figure 2. Waste destination evolution of the Rio de Janeiro State. Source: Lixão-Zero program [5].

advent of Law 12.305/2010 that established the National Policy of Solid Residues (NPSR). The first version of the proposition dates from 1991 and after almost 20 years of discussions was promulgated at the year of 2010.

In Brazil, actually nowadays, the majority of municipalities do not have technical and financial resources to solve the problems related to waste management. Trying to address this matter, the Law No. 11.445/2007 of National Policy of Basic Sanitation and 11.107/2005 of Public Consortiums allowed public authorities to establish agreements among federative entities in order to take advantage and possibilities of cooperation.

Supported by these three regulations, the state of Rio de Janeiro decided to implement a set of programs aimed to eradicate the inadequate destination of solid residues of municipalities. The first and core improvement was the preparation of the Integrated Plan of Solid Residues. The plan is compulsory at NPSR (Art. 18).

To take advantage of Law 11.445, the state threw the "Sanitation Pact" including three subprograms. Two of them are the LIXÃO ZERO (zero open dump) that establish actions to eradication of open dumps until 2014, and the RIO + LIMPO (Rio + Clean) pretending to collect and treat $80 \%$ of wastewater until 2018. The instruments and configurations of the LIXÃO ZERO are presented in the following sections.

Meanwhile, the Rio State created in 2007 and installed in 2009 the State Environment Institute (INEA) to coordinate and extend the activities of the Environment Secretary of State of Rio de Janeiro [6]. The institute is developing municipal sanitation plans for each watershed. The plan is composed at least by 1) infrastructure construction, 2) institutional strengthening and 3) sustainable policies parts.

\subsection{Arrangements and Agreements}

In 2007, under the LIXÃO ZERO program, an entire diagnosis of the waste management system was carried out and from where the regionalization of the waste treatment and the creation of municipal consortiums to implement sanitary landfills and the solid residues treatment centers (CTR's) were idealized.

The State has now eight public consortiums (Table 1) that enclose 41 of the 92 cities of the federative unit, but represent less than $9 \%$ of total waste produced. The majority is economically and demographically small, suffering from technical and financial constrains to give the correct destination to their waste, and the consortium made the construction and/or the operation of a sanitary landfill viable.

The complementary 91\% of the residues produced daily from 53 entities are, after the plan execution, designed to 18 sanitary landfills. The State Capital, Rio de Janeiro, responsible for $53 \%$ of all state waste production, only in 2012 structured the Seropédica landfill to adequate disposal. For almost 20 years, the City of Rio sent their residues to Gramacho open dump ( $\left.22^{\circ} 44^{\prime} 56.63^{\prime \prime} \mathrm{S}, 43^{\circ} 15^{\prime} 31.43^{\prime \prime} \mathrm{W}\right)$, now remediated.

The recent State Law 6.362/2012 defines that landfills could be administered: 1) directly by municipalities, 2) by public concession, 3) by public consortium (Law 11.107/05), 4) by the private sector, since properly authorized. By the same law, the landfills cannot restrict the source of the waste, except the public administered (type 1), or receive hazardous, industrial or healthcare waste unless these are their main objective and they are pre- 
pared to adequately dispose them. Once the city project is viable, others cities can use disposal sites by agreement and by compensating the operator, observed the project limits, since this increment reduces their disposal site lifetime. Next part presents these technical standards.

In practice, the operation is usually made by public concession contract after bidding with all landfill technical specification determined [7]. By now, and due to increasing complexity, there are fewer directly administered MSW landfills and the new entire private ones are also rare.

\subsection{Disposal Sites Location and Configuration}

According to Loureiro et al. [8], in 2005 the waste management structures composition in Rio de Janeiro State was 4 licensed, 6 licensing stage, and 13 controlled/remediated landfills; 57 sorting and composting units, but only 26 operating normally; and 62 open dumps. After the rearrangement in 2014 the situation shall be the outlined by Table 2. It is also expected an increase in inspection and reducing the number of "underground" landfills.

Table 1. Waste management consortiuns created.

\begin{tabular}{cccc}
\hline Consortium & Cities & $\begin{array}{c}\text { Destination } \\
\text { (tonnes/day) }\end{array}$ & \% of State \\
\hline Centro Sul 1 & 5 & 226 & $1.49 \%$ \\
Lagos 1 & 3 & 161 & $1.06 \%$ \\
Noroeste I & 7 & 90 & $0.59 \%$ \\
Noroeste II & 8 & 82 & $0.54 \%$ \\
Serrana 1 & 4 & 154 & $1.01 \%$ \\
Serrana 2 & 6 & 371 & $2.44 \%$ \\
Sul Fluminense 2 & 4 & 126 & $0.83 \%$ \\
Vale do Café & 4 & 147 & $0.97 \%$ \\
Total & 41 & 1357 & $8.93 \%$ \\
\hline
\end{tabular}

Source: LIXÃO-ZERO [6].

Table 2. Landfill waste destination (tonnes/day).

\begin{tabular}{|c|c|c|c|c|c|}
\hline Landfill & Destination & $\%$ State & Landfill & Destination & $\%$ State \\
\hline Angra dos Reis & 174 & $1.08 \%$ & Resende & 126 & $0.78 \%$ \\
\hline Barra Mansa & 363 & $2.25 \%$ & Rio das Ostras & 90 & $0.56 \%$ \\
\hline Belford Roxo & 425 & $2.63 \%$ & Santa Maria Madalena & 73 & $0.45 \%$ \\
\hline Campos & 465 & $2.88 \%$ & São Fidelis & 105 & $0.65 \%$ \\
\hline Cantagalo & 11 & $0.07 \%$ & São Gonçalo & 1011 & $6.26 \%$ \\
\hline Itaboraí & 857 & $5.30 \%$ & São Pedro Aldeia & 341 & $2.11 \%$ \\
\hline Itaperuna & 67 & $0.41 \%$ & São Sebastião do Alto & 9 & $0.06 \%$ \\
\hline Macaé & 171 & $1.06 \%$ & Sapucaia & 102 & $0.63 \%$ \\
\hline Magé & 191 & $1.18 \%$ & Saquarema & 149 & $0.92 \%$ \\
\hline Miguel Pereira & 14 & $0.09 \%$ & Seropédica & 9020 & $55.81 \%$ \\
\hline Nova Friburgo & 155 & $0.96 \%$ & Teresópolis & 154 & $0.95 \%$ \\
\hline Nova Iguaçu & 1410 & $8.72 \%$ & Três Rios & 269 & $1.66 \%$ \\
\hline Paracambí & 226 & $1.40 \%$ & Vassouras & 147 & $0.91 \%$ \\
\hline Piraí & 38 & $0.24 \%$ & Total & 16163 & $100.00 \%$ \\
\hline
\end{tabular}

Source: LIXÃO-ZERO [5]. 
Landfills design, processes, technology and environmental impacts concepts are well documented in literature since the 80's [9] [10]. Design includes volume and legal requirements, sitting, energy and material recovery, final site use, layout, operating plans, final cover system, but also leachate, groundwater and gas assessment and management. Operation includes, assurance, landfill equipment, personnel, safety and quality control. Landfills also need closure and post-closure care [11].

According to IPCC [12] landfill methane production can vary depending on the disposal practices classified from managed anaerobic (MCF = 1.0) scavenging and some control of fires, and cover material, mechanical compacting or leveling the waste, to unmanaged swallow aerobic-open dumps which have depths of less than 5 meters $(\mathrm{MCF}=0.4)$. Part of the landfill gas $(\mathrm{LFG})$ can be recovered and combusted in a flare or energy device. If left uncontrolled, LFG can lead to smog formation and air pollution and can pose an explosion hazard [13].

The guideline DZ-041-R.13 and the instruction IT-1302-R.1 describe what is necessary to elaborate the environmental impact study and the technical instructions to licensing and operation of a landfill at Rio de Janeiro State, both issued by INEA. The INEA use these technical instructions in order to guide design, bid and authorize the 27 landfills presented in Table 2.

These landfill standards include locations restrictions, geomembrane and two feet of compacted clay soil lining the bottom and the releases at underlying soil, collection, removal and treatment systems of leachate. The operation includes scavenging, compacting, and waste covering procedures.

However, the LFG shall also be monitored, drained and burned in a flare or energy device but the procedure is not mandatory. The collection system is the typical LFG extraction well, more than horizontal trenches. Flares are usually designed open (candlestick).

Despite of the standards, Marques [7] visited five of these sanitary landfills to verify possible differences in procedures and the results are surprising. Four of these five landfills do not treat the LFG adequately. Not even a LFG burning at flares. The study also found some operational pitfall especially in rainy days due to problems with quality, access and operation of machinery.

In resume, the preferred model of Rio de Janeiro for the waste disposal is the IPCC (2006) managed-anaerobic landfill. This means that in the next years the methane correction factor (MCF) shall increase. The strategy adopted provides for the GHG reduction by the recovery of LFG for direct use or combustion in flares or energy devices. The strategy is well defined but not yet so well executed.

\subsection{Economic Instruments}

In order to ease the planning implementation, beyond the technical support, the government designed two different economic instruments: 1) ICMS Verde green sales tax; 2) Treated Waste Purchase Program (TWPP).

In fact, ICMS Verde is not a new tax. The instrument only increase the municipality share at regular distributed revenue from state sales taxation according to environmental addressed issues. To qualify to receive the funds, municipalities must have a municipal system for the environment, composed by 1) an executing agent, 2) a council, 3) a fund and 4) an environmental guard.

The estimative for 2013 distribution of ICMS Verde is US\$88M, but only US\$18M is the counterpart for the MSWM. That is because according to the ICMS Verde (Law no. 5.100) the main objectives of ICMS Verde are: 1) reimburse the municipalities by the use restriction of their territory due to natural conservation areas; 2) reward the municipalities by the realized investments at environmental matters. Pragmatically, resources are distributed according to the following criteria: $45 \%$ for natural conservation units, $30 \%$ for investments in water quality and, $25 \%$ for solid waste management (SEA, 2012). The value of US\$18M denotes some room to subsidized investment in waste management, since one fourth of US\$ 88M is equal to US\$ 22M.

Through TWPP the State pays US\$ 10 per tonne of municipal waste destined adequately. The TWPP is temporary and only for municipalities that already have open dumps. This value is intended to help municipalities during the phase of change to adequate destination to disposal sites. In order to compare, according to Carvalho et al. (2012), the cost of waste regular collection and transfer at the city of Rio de Janeiro is around US\$ 48.00/tonne.

In other hand, the economic instruments to foster LFG extraction, biogas production or energy solution are not yet designed. The most common way to finance projects in LFG area is the trough a clean development mechanism under Kyoto Protocol. Rodrigues \& Martins [14] affirm that beyond the access to "carbon credit market" there is not by the government any different treatment or subsidies to the landfill energy or biogas (differentiated 
gas and energy price or taxes). Rather, potential investors in this technology face numerous obstacles including: financing difficulties, equipment costs and often imported.

\subsection{Waste Characterization and Recycling Rates}

The City of Rio de Janeiro is responsible for almost half of the waste production at Rio de Janeiro State. The city is also the unique municipality that maintains a 20 years information system about waste composition [15]. The Figure 3 depicts the 2010 waste composition and production per habitant/day.

South region (blue) is the richest and properties hedonic value decreases from east to west radially. Downtown and seaport (pink) incorporates also some industrial facilities that distort waste production. However, waste composition is relatively stable through regions, and also in 10 years time series [15]. Since the waste of the city of Rio de Janeiro is relevant, representative, relatively stable and the only information available, this study extrapolates the composition data to the rest of State to draw some conclusions. This is a limitation of every Rio de Janeiro State study.

In Brazil, only $10 \%$ of 5564 and in Rio de Janeiro 22 of the 95 municipalities have some kind of selective collection, but only 8 embrace their entire territory and 6 have sociocultural programs [3]. Some apartment complexes already applies the selective collection but COMLURB mixture them at collection truck.

As a result, reuse and recycling rates are negligible. Per example, Rio de Janeiro city only selectively collect 25 tonnes/day $(0.27 \%)$, with the modest goal to increase the rate to $3.5 \%$ until 2016 . Of the total materials with the potential of recycling, only $3 \%$ is recovered [17].

\section{Methane Potential Production and Recover Initiatives}

\subsection{Greenhouse Gas Inventories Changes}

With the input of the a) parameters; b) methane correction factor (MCF) considering the distribution of disposal sites types of Graphic 1-anaerobic managed (1.0) and unmanaged deep (0.8); and c) activity data, the 2006 IPCC Software for National Greenhouse Gas Inventories (IPCC, 2012) returned a CH4 generation of 4584 $\mathrm{GgCO}_{2} \mathrm{eq}$ for 2012. This estimative is very near of some other studies [18]-[20].

These studies' calculations do not consider any remediation, industrial waste, wastewater, sludge or methane recovery because of their aim, relevance or because they are very recent. The difference among them is in time and in the waste composition (DOCf) or it disposal type classifications (MCF) factors, and not at activity data. Then, if the status quo of unmanaged disposal sites $(\mathrm{MCF}=0.6)$ were maintained, with the same activity data and using the same software, the 2012 methane emission would be 3192 in $\mathrm{GgCO}_{2} \mathrm{eq}$. Thus, the change in the solid waste disposition profile since 2007 shall result in an increase of $43.6 \%$ in methane production potential.

The Loureiro [18] study analyzed the possible results of "climate change policies, plans, and the government programs” in MSW emissions, establishing three different scenarios to estimate the emissions from 2005 until 2030. The emissions and reduction potential in future scenarios are depicted in Table 3.

- Scenario A-with no intervention to minimize GHG emissions;

- Scenario B-that includes already planned actions and policies. That was, $100 \%$ collection $80 \%$ methane recovery and controlled burn in flairs; and

- Scenario C-is where all preliminary planned and the government goals were archived with emission reduction by 65\% compared to 2005, eradicate the use of open dumps by 2014 and their remediation by 2016.

The study concludes that "there are many different procedures and technologies to treat solid waste, but in Brazil, landfilling seems to be a good solution for waste treatment in the coming years, to the extent that more economical and environmentally adequate solutions are not possible to implement”.

Table 3. Emissions in future scenarios for solid waste in the state of Rio de Janeiro $\left(\mathrm{GgCO}_{2} \mathrm{eq}\right)$.

\begin{tabular}{cccccc}
\hline Scenario & 2010 & 2015 & 2020 & 2025 & 7415 \\
A & 5152 & 5890 & 6620 & 2030 & 2729 \\
B & 4032 & 3797 & 3432 & 1774 \\
C & 3771 & 2248 & 1501 & 1695 \\
\hline
\end{tabular}

Source: Loureiro et al. (2013). 


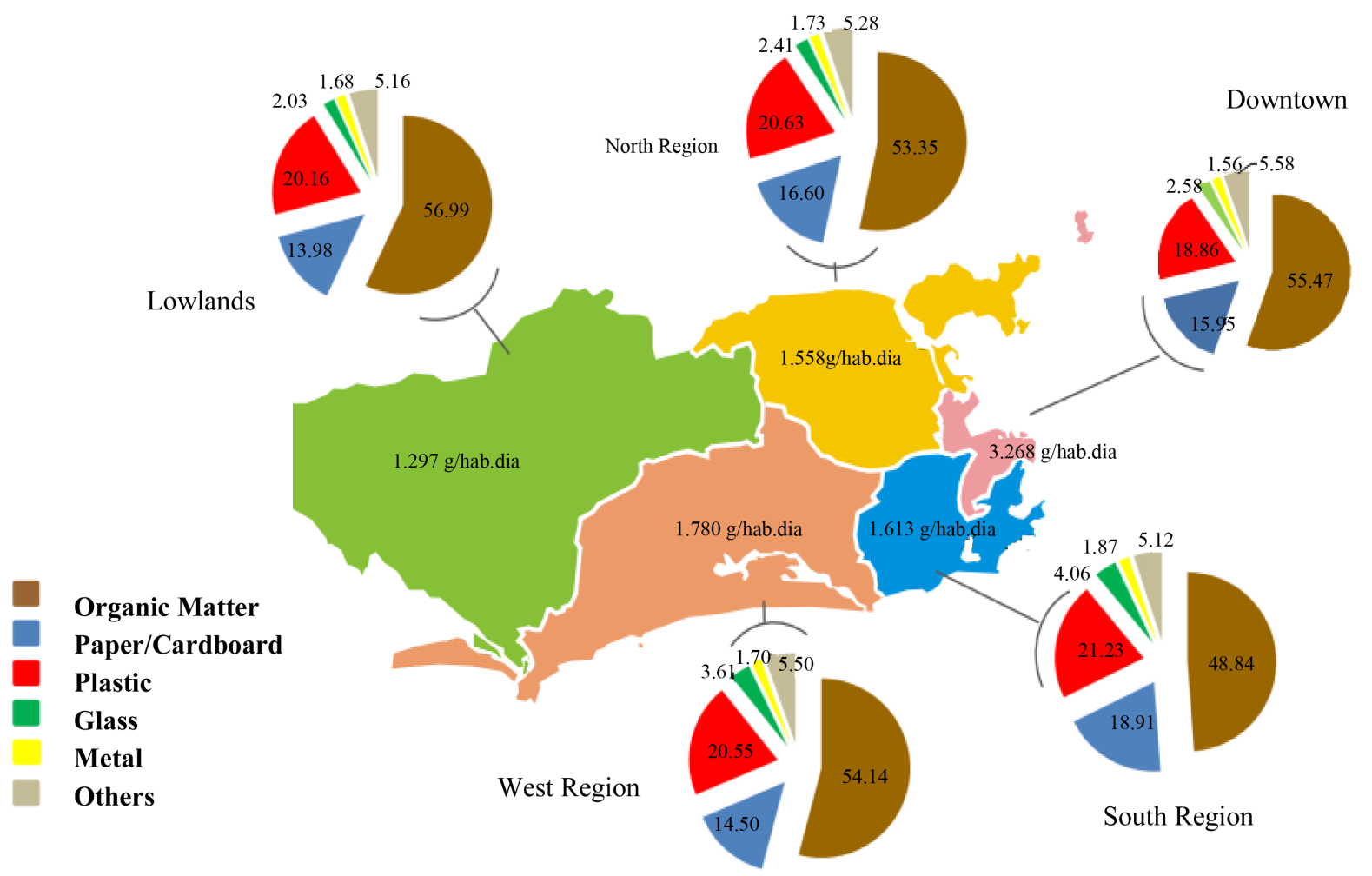

Figure 3. Waste composition and production. Source: Fonti [16].

\subsection{Waste-to-Energy Initiatives}

According to Kyoto Protocol, Brazil is one of the countries of the Annex 2, and eligible to develop clean development mechanisms (CDM) and issue of certified emission reduction (CER). Half of CDM projects are from renewable energy sector (eolic, solar, etc.) and only $9 \%$ come from landfills projects. However, this portion of landfill projects represents $23 \%$ of the Brazil total reduction or 73 million tonnes of $\mathrm{CO}_{2} \mathrm{eq}$ and is the main motivator of solutions development beyond command and control tools, as standards [14] [19] Rio de Janeiro State has few waste-to-energy initiatives related to MSWM.

In 2012, the remediated open dump of Gramacho, where the city of Rio de Janeiro sent their waste for almost 20 years, hosts an initiative to recover the methane and send it to petroleum refinery of Duque de Caxias, $6 \mathrm{~km}$ far from the site. The private initiative expects to recover $200.000 \mathrm{~m}^{3} /$ day of biogas during 15 years from 300 vertical wells installed over the open dump. The production is $70 \%$ of total methane used at the refinery.

The only two others waste projects refer to local thermoelectric power plants NovaGerar and UsinaVerde.

The project NovaGerar is a Kyoto Protocol Clean Development Mechanism (CDM) which has the objective to reduce GEE emissions, mainly methane of Nova Iguaçu City new landfill. That reduction could happen through local electric energy generation, gas distribution network or controlled methane combustion at flares. At the very beginning of the project based on a conservative study, the managers decided to abandon the energy generation and elect to controlled combustion solution. The estimated capacity of the plant would be about 4 MW [21].

The other CDM project is the technologic experiment Usina Verde. UsinaVerde is an incinerator with the input capacity of 30 tonnes of pre-treated waste daily and produces about $700 \mathrm{~kW}$ (gross). The commercial module is designed to receive 150 tonnes of waste, equivalent to a small city of 7500 residential units and to produce $2 \mathrm{MW}$ of energy.

\section{Conclusions}

The aim of this paper is to depict the context, the criteria and discuss the adopted strategies to MSWM. Results 
reveal that the main motive for the revolutionary management of the solid waste was the regulatory environment which prohibited the improper disposal of waste after 2014. This same regulatory environment also stipulates the objective of "no generation, reduction, reuse, recycling and solid waste treatment and environmentally adequate disposal of unserviceable waste", which means, adequate landfilling "after all possible treatment and recovery by technological processes available and economically feasible".

But, among other factors, "technologically available" and "economically feasible" depend on a plan to make them available and viable. The plans, in turn, depend on subjective view, will, beliefs and political interests of the stakeholders. The results of this study show that the practitioners, managers, academics and government may be underestimating goals and supporting future scenarios in constraints and barriers of present context, which are in their duty to remove. In our case study it becomes evident that the goals of reducing waste are extremely modest and technological processes available for recovery and waste treatment were limited by economic factors. This would be understandable, but not within a 20-year planning.

It is obvious that landfills' configuration model of Rio de Janeiro predominates the public health approach, even because the competence of those responsible for waste management (municipalities) is dependent on the actions of other economic agents to enable and provide the necessary technology for more efficient management of waste. Afterwards, only open dumps eradication is mandatory. It is even uncomfortable to verify that the managers and researchers currently tout the extraction of LFG as the optimal solution to the waste management, and their potential for biogas production is viewed with great enthusiasm.

Among the problems arising from this approach, studies predict the increase of landfill numbers and sizes, management cost, environmental and leachate impact, post-closure care and contaminating life-span. Plus, landfills become unavailable for any use for over two decades (agriculture, construction, etc.) and, after all, the landfilling overcapacity can truncate the perception of the need for reducing, reuse and recycling.

The design of a federal policy that increments the competitiveness of other waste technologies and favors the landfilling reduction and energy recover is urgent. These actions include, differential pricing, import tax breaks, subsidies and more aggressive lines of financing. Anyway, the planning should be more coordinated and go further.

\section{Acknowledgements}

This research received no specific grant from any funding agency in the public, commercial, or not-for-profit sectors.

\section{References}

[1] EPA (2014) Municipal Solid Waste Generation, Recycling and Disposal in the United States: Facts and Figures for 2012. EPA, Washington DC.

[2] Diaz, R. and Otoma, R. (2013) Constrained Recycling: A Framework to Reduce Landfilling in Developing Countries. Waste Management and Research, 31, 23-29. http://dx.doi.org/10.1177/0734242X12465461

[3] IBGE (2010) Pesquisa Nacional de Saneamento Básico. http://www.ibge.gov.br/home/estatistica/populacao/condicaodevida/pnsb2008/PNSB_2008.pdf

[4] EUROSTAT (2014) In 2012, 42\% of Treated Municipal Waste Was Recycled or Composted. EUROSTAT Press Office, Luxembourg.

[5] SEA (2012) LIXÃO ZERO. http://www.rj.gov.br/web/sea/exibeconteudo?article-id=926885

[6] SEA (2012) Atribuições e Gestão Ambiental. http://www.rj.gov.br/web/sea/exibeconteudo?article-id=157524

[7] Marques, F. (2010) The Operational Proceeding Evaluations of Sanitary Landfills of Rio de Janeiro State. Rio de Janeiro.

[8] Loureiro, S., Rovere, E. and Mahler, C. (2013) Analysis of Potential for Reducing Emissions of Greenhouse Gases in Municipal Solid Waste in Brazil, in the State and City of Rio de Janeiro. Waste Management, 33, 1302-1312. http://dx.doi.org/10.1016/j.wasman.2013.01.024

[9] Christensen, T. (1989) Sanitary Landfilling: Process, Technology and Environmental Impact. T. Christensen, Ed., Elsevier Inc., Amsterdam.

[10] EPA (1997) EPA/600/R-95/146. EPA, Washington DC.

[11] EPA (1995) Decision Maker's Guide to Solid Waste Management, Volume II, (EPA 530-R-95-023). EPA, Washington 
DC.

[12] IPCC (2006) 2006 IPCC Guidelines for National Greenhouse Gas Inventories. http://www.ipcc-nggip.iges.or.jp/public/2006gl/vol5.html

[13] EPA (2011) Project Development Handbook. http://www.epa.gov/outreach/lmop/publications-tools/handbook.html

[14] Rodrigues, A. and Martins, G. (2008) Generation of Energy from the Biogas Generated in Landfills in Brazil: Potential, Legal Frameworks, Incentives and Projects. Revista AIDIS de Ingeniería y Ciencias Ambientales: Investigación, desarrollo y práctica, 1.

[15] COMLURB (2009) Microbiologic and Gravimetric Characterization of Rio de Janeiro MSW. Applied Research Department, Rio de Janeiro.

[16] Fonti, A.N. (2010) Rio de Janeiro MSW Panorama. COMLURB, Rio de Janeiro Cleaning Company, Rio de Janeiro.

[17] Bastos, I. (2013) Comlurb and Public Ministry Fights for Selective Garbage Cans. Jornal O Globo, 17.

[18] Loureiro, S., Rovere, E. and Mahler, C. (2013) Analysis of Potential for Reducing Emissions of Greenhouse Gases in Municipal Solid Waste in Brazil, in the State and City of Rio de Janeiro. Waste Management, in Press. http://dx.doi.org/10.1016/j.wasman.2013.01.024

[19] MCT (2010) II Brazilian Inventory of Anthropogenic Emissions and Removals of Greenhouse Gases Not Controlled by the Montreal Protocol. Ministry of Science and Technology, Brasília.

[20] Rovere, E., Dubeux, C., Oliveira, L. and Wills, W. (2007) Emissions Inventory of Greenhouse Gases in the State of Rio de Janeiro. PPE/COPPE/UFRJ, Rio de Janeiro.

[21] Gutierrez, M. (2010) Sectorial Development Mechanism: Perspectives for Brasilian Sustainable Development. Center for Studies on Inequality and Development, Niterói. 
Scientific Research Publishing (SCIRP) is one of the largest Open Access journal publishers. It is currently publishing more than 200 open access, online, peer-reviewed journals covering a wide range of academic disciplines. SCIRP serves the worldwide academic communities and contributes to the progress and application of science with its publication.

Other selected journals from SCIRP are listed as below. Submit your manuscript to us via either submit@scirp.org or Online Submission Portal.
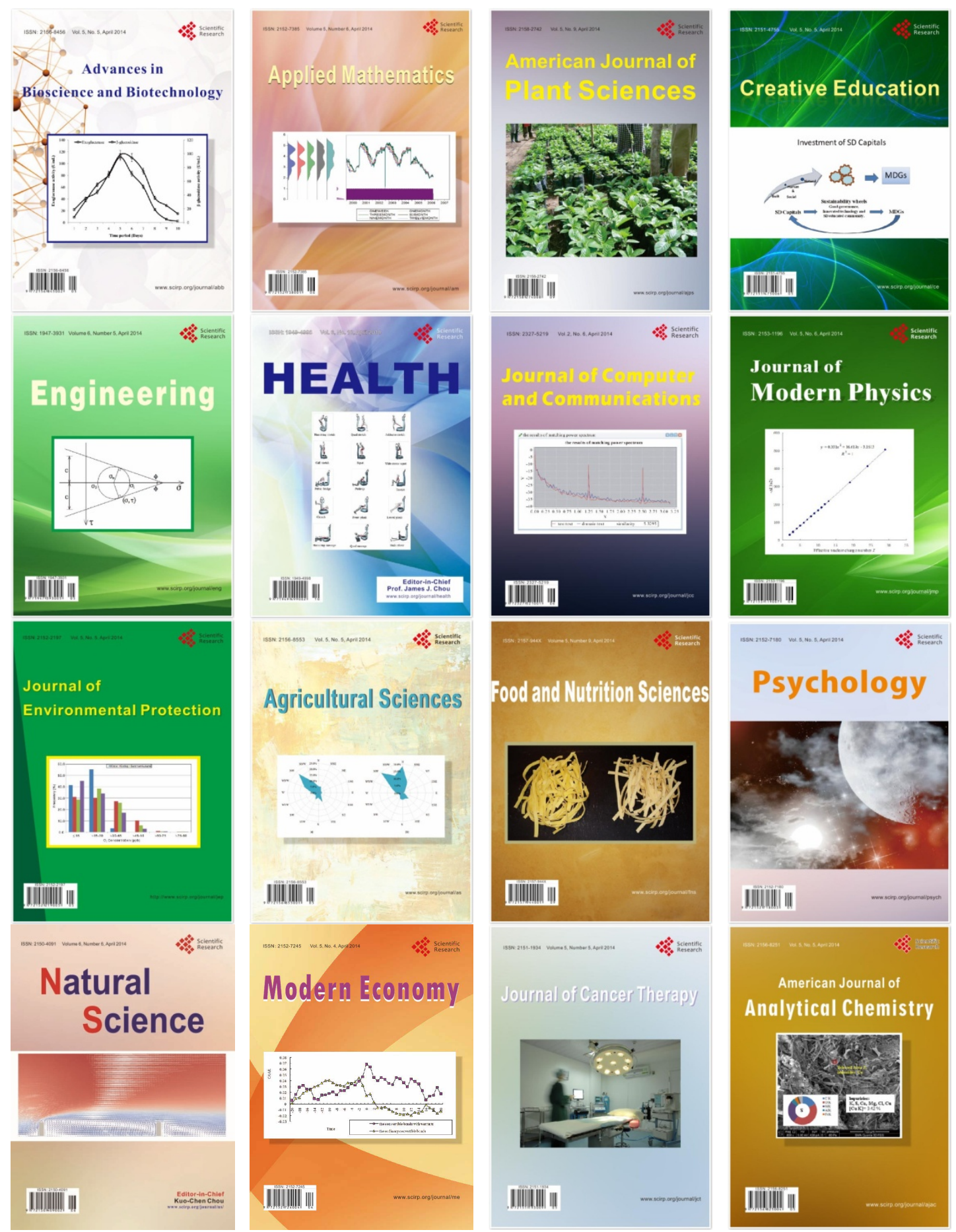